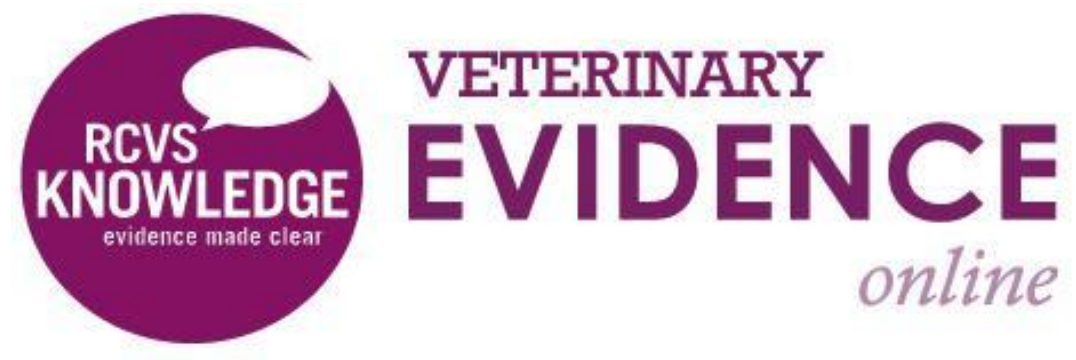

\title{
Are Dogs That Are Fed from a Raised Bowl at an Increased Risk of Gastric Dilation Volvulus Compared with Floor-Fed Dogs?
}

\author{
A Knowledge Summary by \\ Louise Buckley PhD RVN ${ }^{1 *}$ \\ ${ }^{1}$ Harper Adams University, Edgmond, Newport TF10 8NB
${ }^{*}$ Corresponding Author (l$\underline{\text { lbuckley@harper-adams.ac.uk) }}$
}

ISSN: 2396-9776

Published: 2017

in: Vol 2, Issue 1

DOI: http://dx.doi.org/10.18849/ve.v2i1.57

Reviewed by: Wanda Gordon-Evans (DVM, PhD, DACVS) and Bruce Smith (BVSc, MS, FANZCVS, DACVS) 


\section{Clinical bottom line}

There are only two studies that study the effect of raised feeders on the risk of Gastric Dilatation Volvulus (GDV) and their findings conflict. Only one study found a significant effect of feeder height, with large and giant breeds fed from a raised feeder being at an increased risk of GDV floor fed dogs. However, these authors found that, where the feeder was raised, the height of the feeder that increased the GDV risk was affected by the size of the dog. Large breed dogs were more likely to develop a GDV if fed from a bowl $\leq$ 1 foot tall, whereas giant breed dogs were more likely to develop a GDV if fed from a bowl $>1$ foot tall. No studies found that feeding from a raised feeder reduced the risk of GDV relative to feeding from the floor. Therefore, the safest option in the absence of further evidence is to advise that owners of 'at risk' dogs feed from a feeder on the floor. This may not reduce the risk of GDV, but there is no evidence to suggest that it will increase the risk.

\section{Question}

Are dogs that are fed from a raised bowl at an increased risk of gastric dilation volvulus (GDV) compared with dogs that are fed from a bowl on the floor?

\section{Clinical Scenario}

Raised feeding bowls are available commercially and are sometimes recommended by veterinary nurses to assist elderly arthritic dogs to comfortably access their feed ration. A client with an elderly dog is attending a senior wellbeing clinic and asks for advice on whether they should use one of these feeders. The dog is a large or giant breed dog of the type at increased risk of developing a gastric dilation volvulus.

\section{The Evidence}

The literature searches uncovered two papers (Glickman et al. 2000; Pipan et al. 2012) that directly addressed the PICO question. Of these, one of the studies (Pipan et al., 2012) found no significant effect of feeder height on risk of having a GDV episode. One paper (Glickman et al., 2000) found that dogs that were fed from a raised bowl were significantly more likely to present at a clinic with a GDV episode. However, the height of the bowl that increased the risk differed according to whether the dog was a large or giant breed. No studies found a decreased risk of GDV as a consequence of feeding a dog from a raised bowl.

\section{Summary of the evidence}

\begin{tabular}{|l|l|}
\hline Glickman (2000) Population: & $\begin{array}{l}\text { Dogs (male, female, neutered and entire) from eleven different large } \\
\text { and giant dog breeds (Akita, Bloodhound, Collie, Great Dane, Irish } \\
\text { Setter, Irish Wolfhound, Newfoundland, Rottweiler, Saint Bernard, } \\
\text { Standard Poodle, and Weimaraner), that were located within the } \\
\text { USA. Dogs were required to be at least } 6 \text { months old and not to have } \\
\text { a medical history that included an episode of GDV before the study } \\
\text { commenced. }\end{array}$ \\
\hline Sample size: & 1637 (large breeds: $\mathrm{n}=894$; giant breeds: $\mathrm{n}=743$ ): \\
\hline
\end{tabular}




\begin{tabular}{|c|c|}
\hline & $\begin{array}{l}\text { Dogs that developed a GDV during the course of the study: } \\
98 \\
\text { Dogs that did not develop a GDV during the course of the } \\
\text { study: } 1539 \\
\text { Nb. This study was derived from a larger prospective cohort study } \\
\text { carried out by the authors. } 1991 \text { dogs initially enrolled on this study; } \\
\text { however, for inclusion in the current study, dogs needed to be } 6 \\
\text { months or older, and owners needed to have provided vital status } \\
\text { information (undefined in the paper) and have completed the } \\
\text { detailed questionnaire initially sent out to owners. }\end{array}$ \\
\hline Intervention details: & 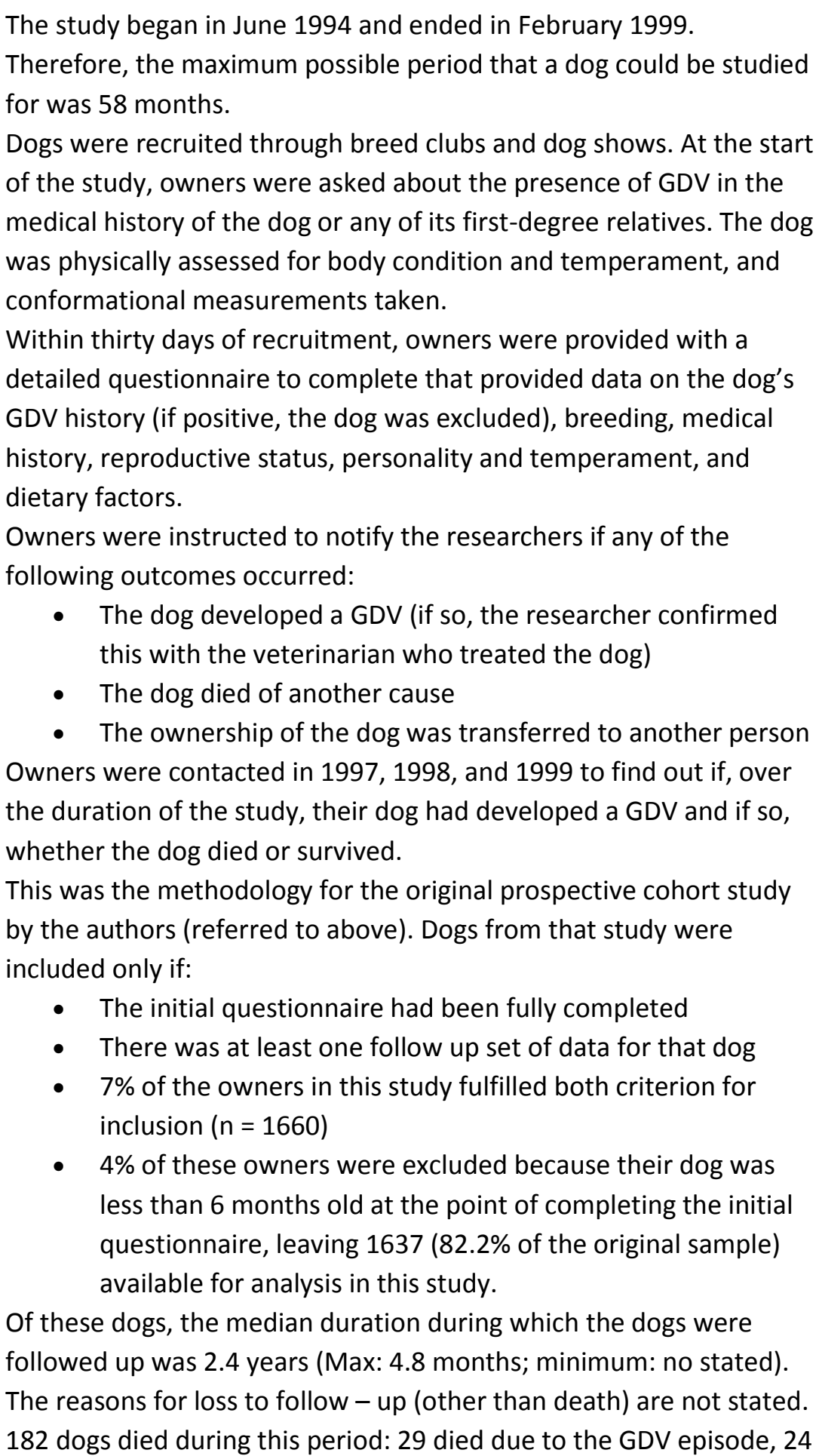 \\
\hline
\end{tabular}




\begin{tabular}{|c|c|}
\hline & $\begin{array}{l}\text { died for unknown reasons. } 55 \text { are reported to have died from other } \\
\text { medical problems. } 74 \text { dogs are not accounted for in the figures } \\
\text { reported. }\end{array}$ \\
\hline Study design: & Prospective cohort study \\
\hline Outcome studied: & $\begin{array}{l}\text { The outcome measure was whether the dog developed an episode } \\
\text { of GDV during the course of the study and whether it survived this } \\
\text { episode. The study then looked for non-dietary related factors that } \\
\text { were associated with an increased risk of developing GDV in the } \\
\text { population studied. } \\
\text { Of relevance to this PICO, the authors' asked owners about the } \\
\text { height from which they fed their dog. From this, they derived two } \\
\text { specific aspects to assess for risk: } \\
\text { 1. Was the food bowl raised? } \\
\text { - Yes / No } \\
\text { 2. What was the height of the food bowl? } \\
\text { - Not raised / raised } \leq 1 \text { foot / raised }>1 \text { foot } \\
\text { In analysing and presenting the data, the authors split the data } \\
\text { according to the size of the dog: } \\
\text { 1. Large breed dogs } \\
\text { 2. Giant breed dogs }\end{array}$ \\
\hline $\begin{array}{l}\text { Main findings: } \\
\text { (relevant to PICO question): }\end{array}$ & 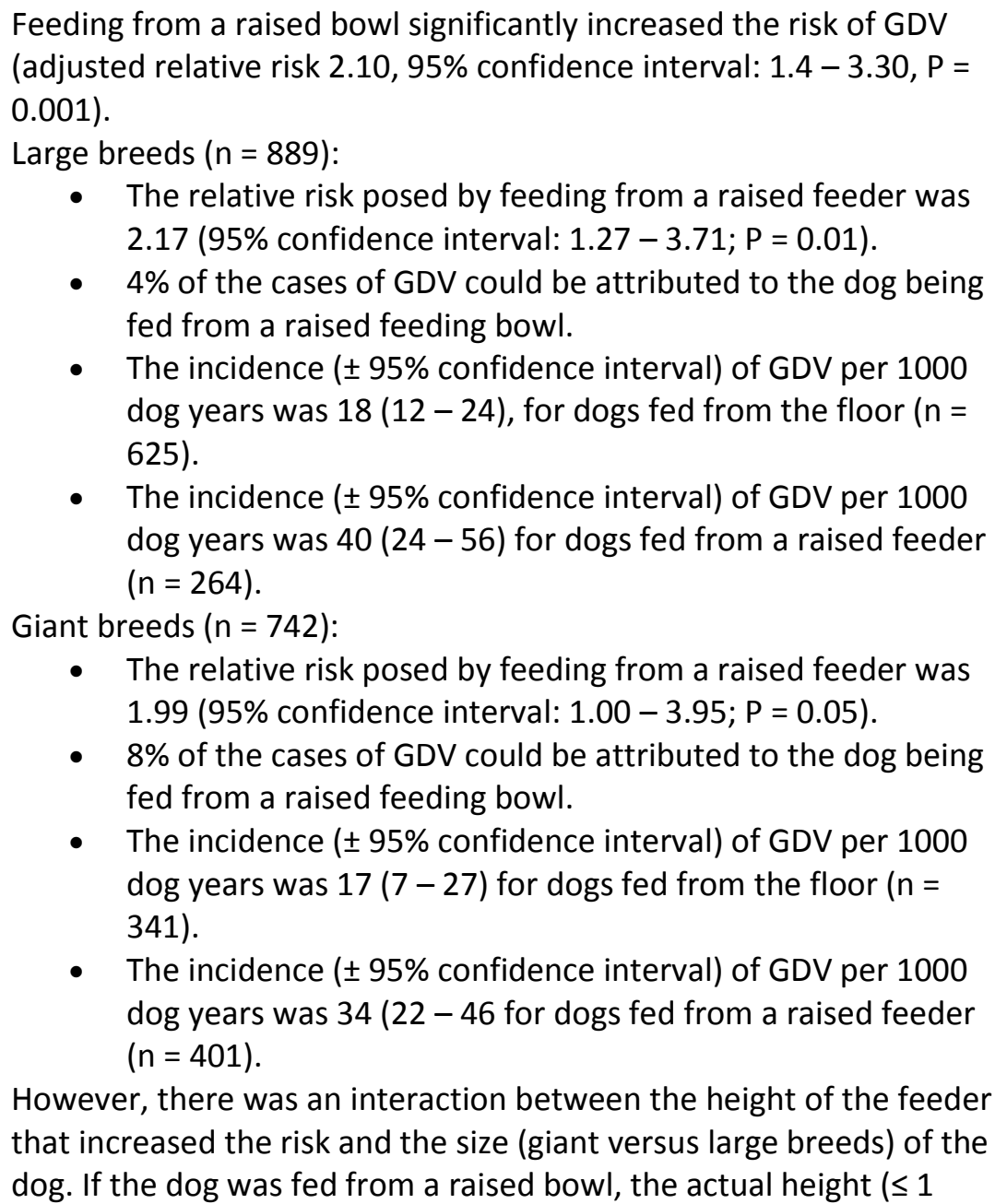 \\
\hline
\end{tabular}




\begin{tabular}{|c|c|}
\hline & $\begin{array}{l}\text { foot high versus }>1 \text { foot high) of the bowl significantly affected } \\
\text { relative risk: } \\
\text { - Large breeds: Dogs that were fed from a bowl } \leq 1 \text { foot high } \\
\text { ( } n=105) \text { were } 3.06 \text { times ( } 95 \% \text { confidence interval: } 1.60- \\
5.87, P=0002) \text { more likely than dogs that were not fed from } \\
\text { a raised bowl ( } n=625 \text { ) to experience a GDV. } \\
\text { - The incidence }( \pm 95 \% \text { confidence interval) of GDV per } 1000 \\
\text { dog years was } 56(26-86 \text { ) for dogs fed from a bowl } \leq 1 \text { foot } \\
\text { high. } \\
\text { Dogs that were fed from a bowl }>1 \text { foot high ( } n=144 \text { ) were } \\
\text { no more likely to experience a GDV than dogs not fed from a } \\
\text { raised bowl ( } n=625) \text {. } \\
\text { The incidence }( \pm 95 \% \text { confidence interval) of GDV per } 1000 \\
\text { dog years was } 29(-11-47) \text { for dogs fed from a bowl }>\text { than } \\
1 \text { foot high. } \\
\text { Giant breed dogs: } \\
\text { Dogs that were fed from a bowl } \leq 1 \text { foot high ( } n=60) \text { were } \\
\text { no more likely to experience a GDV than dogs not fed from a } \\
\text { raised bowl ( } n=341) \text {. } \\
\text { The incidence }( \pm 95 \% \text { confidence interval) of GDV per } 1000 \\
\text { dog years was } 15(-6-36) \text { for dogs fed from a bowl } \leq \text { less } \\
\text { than } 1 \text { foot high. } \\
\text { Dogs that were fed from a bowl }>1 \text { foot high ( } n=324) \text { were } \\
2.29 \text { times ( } 95 \% \text { confidence interval: } 1.15-4.58, P=0.02) \\
\text { more likely than dogs that were not fed from a raised bowl } \\
\text { ( } n=341 \text { ) to experience a GDV. } \\
\text { The incidence }( \pm 95 \% \text { confidence interval) of GDV per } 1000 \\
\text { dog years was } 39(25-53 \text { ) for dogs fed from a bowl }>1 \text { foot } \\
\text { high. }\end{array}$ \\
\hline Limitations: & $\begin{array}{l}\text { The authors collect data on feeding height at the start of the study } \\
\text { (within } 30 \text { days of recruiting dogs). No further attempts were made } \\
\text { to collect further data on this at regular intervals. Thus, the authors } \\
\text { cannot be certain that the dogs were being fed from a height at the } \\
\text { time at which it developed a GDV (up to } 58 \text { months later). This } \\
\text { reduces the ability of the study to detect real effects or meaningfully } \\
\text { explain the effects observed. } \\
\text { The authors do not examine interactions between: } \\
\text { - Speed of eating and the height of the feed bowl } \\
\text { - Morphometric measurements (particularly height of the } \\
\quad \text { dog) and speed of eating } \\
\text { The total number of dogs lost to follow up is not reported. The } \\
\text { authors exclude dogs from the original study that were lost to follow } \\
\text { up before at least one follow up questionnaire was completed. } \\
\text { However, this is not the same as saying these dogs were not lost to } \\
\text { follow up as, for example, if the study was still in operation, why } \\
\text { were further questionnaires not completed by these owners? The } \\
\text { authors do not report how many dogs recruited to the study, } \\
\text { remained with the study until the study ended. Instead they report } \\
\text { only median duration of follow up; this is meaningless to assess the } \\
\text { number of dogs that remained with the study from recruitment to } \\
\text { study end, as the dogs were signed up to the study at different time }\end{array}$ \\
\hline
\end{tabular}




\begin{tabular}{|l|l|}
\hline points. If the dogs that developed GDV and the dogs that didn't \\
develop a GDV differentially dropped out prematurely, this could \\
introduce a 'loss to follow up bias'. We know that, by the nature of \\
the recruitment process for the subset of dogs included in this study, \\
that already 13.3\% of dogs had been excluded due to lack of follow \\
up data (no follow up questionnaires completed). Therefore, it \\
seems likely that total losses to follow up before the study ended \\
would be higher (and possibly considerably so) but the authors fail \\
to give us the information needed to assess this. \\
There is not attempt by the authors to assess whether participant \\
drop out before the study ended was random or whether particular \\
risk factors or characteristics were associated with an increased risk \\
of drop out. Furthermore, there are a lot of dogs lost to death that \\
remain unaccounted for in the authors' reporting.
\end{tabular}

\begin{tabular}{|c|c|}
\hline \multicolumn{2}{|l|}{ Pipan (2012) } \\
\hline Population: & $\begin{array}{l}\text { Privately owned dogs (any breed or mix, both sexes, neutered and } \\
\text { entire) across a wide geographic area. } \\
\text { The survey was potentially available to English speaking dog owners } \\
\text { with access to the internet in any country worldwide. }\end{array}$ \\
\hline Sample size: & $\begin{array}{l}2551 \text { surveys included in the analysis: } \\
\text { - Control group (dogs without a GDV): } 1437 \text { respondents } \\
\text { - Gastric dilation-volvulus group (GDV): } 1114 \text { respondents }\end{array}$ \\
\hline Intervention details: & $\begin{array}{l}\text { Online survey based study, with ad hoc convenience sampling of dog } \\
\text { owners. } \\
\text { The questionnaire was divided into three sections: } \\
\text { 1. Demographic information (year of birth, breed, sex, neuter } \\
\text { status, and purpose of the dog; country and postcode of } \\
\text { respondent). Whether the dog had ever had a GDV that } \\
\text { required surgical intervention. This latter question was used } \\
\text { to divide dogs into the control group and the GDV group. } \\
\text { However, the authors then also included within the GDV } \\
\text { group dogs that did not have surgery, or died / were } \\
\text { euthanised without surgery but were considered to have a } \\
\text { GDV (whether confirmed or presumed). } \\
\text { 2. GDV group: a series of } 44 \text { questions divided into } 4 \\
\text { categories: } \\
\text { i. Dog specific factors } \\
\text { ii. } \quad \text { Management factors } \\
\text { iii. } \quad \text { Environmental factors } \\
\text { iv. Personality factors } \\
\text { 3. Control group: The same questions were asked of the } \\
\text { control group dog owners as were asked of the GDV group, } \\
\text { with the exception that they were not asked any questions } \\
\text { about the GDV episode (as the dogs had not experienced a } \\
\text { GDV). They were asked one additional question (had the dog } \\
\text { had a prophylactic gastroplexy?). These changes reduced the } \\
\text { total number of questions asked to } 32 \text {. }\end{array}$ \\
\hline Study design: & Cross-sectional study \\
\hline
\end{tabular}




\begin{tabular}{|c|l|}
\hline Outcome studied: & $\begin{array}{l}\text { The outcome measure was a GDV episode in the dog's history. The } \\
\text { study looked for factors that were associated with an increased } \\
\text { incidence of GDV in the population studied. } \\
\text { Of relevance to this PICO, the authors' asked owners whether the } \\
\text { dog was fed from a raised bowl. }\end{array}$ \\
\hline Main findings: & $\begin{array}{l}\text { The findings in relation to raised bowl feeding are not reported } \\
\text { within the results section. The authors note in the discussion that } \\
\text { feeding from a raised bowl was not significantly associated with the } \\
\text { risk of developing a GDV. }\end{array}$ \\
\hline Limitations: & $\begin{array}{l}\text { The primary limitation is the failure to report their findings (along } \\
\text { with numerical data) within the results section as this precludes the } \\
\text { reader making an independent assessment of their conclusion. } \\
\text { The incidents of GDV were retrospective so owners may have } \\
\text { already taken measures to alter their height from which their dog } \\
\text { was fed post-surgery, on the basis of veterinary recommendation or } \\
\text { lay research. The authors do not outline whether owners were asked } \\
\text { to complete the form on the basis of the height the dog was fed } \\
\text { from at the time (or preceding) the GDV or, present time, or not } \\
\text { directed as to a time frame to use. } \\
\text { There was no attempt to match control and GDV cases across other } \\
\text { dimensions that may have been relevant (e.g. breed, size, and / or } \\
\text { age). } \\
\text { The population of dogs studied is not constrained to types of dogs at } \\
\text { high risk of GDV (large and giant breed dogs). Therefore, if any risk } \\
\text { factors identified co-vary with the size of the dog, this would } \\
\text { represent a confounding variable in interpreting the data that limits } \\
\text { any conclusions that may be drawn. }\end{array}$ \\
\hline
\end{tabular}

\section{Appraisal, application and reflection}

Only two studies were identified that addressed the PICO question and these two studies were not in agreement. Thus, the evidence base for answering the question is relatively limited. However, it is pertinent to observe that neither study identified feeding dogs from the floor as a risk factor for GDV. It is also pertinent to note that most studies that investigate risk factors for a GDV have found that there are many factors that have been found to be significantly implicated as associated with an increased risk of GDV. It is beyond the scope of this Knowledge Summary to discuss these but it should be borne in mind by the reader when considering the discussion below and the clinical bottom line provided.

Of the two studies, the Pipan et al. (2012) provides the more impressive sample size for GDV dogs $(n=1114)$, compared with the Glickman et al. study $(n=98)$. However, despite this, it is difficult to conclude much about the findings by Pipan et al. (2012). The authors provide scant information to support either how they investigated feeder height as a risk factor or what they found. The only reference by the authors to their findings in relation to the PICO can be found in the discussion section. They provide no numerical information to allow the reader to evaluate this finding (e.g. was there a statistical tendency for the dogs fed from a feeder to have an increased or decreased risk of GDV?).

The study by Glickman et al. (2000) provides more comprehensive statistical reporting of the data relevant to the PICO question, but provides incomplete reporting of the dogs lost to follow up. Follow up losses are likely to be high given that $13.3 \%$ of the dogs lost to follow up had already been lost during the primary study that this study data was drawn from. This should be considered as it may severely distort the data if the losses were not randomly distributed across the categories of dogs in relation to this PICO question. In this study, feeding from a raised bowl was identified as a risk factor for both large and giant breed dogs. Furthermore, 
there was an interaction between feeder height and whether the dog was a large or giant breed dog. Specifically, lower raised feeders ( $\leq 1$ foot) increased the risk for large breed dogs (but not higher raised feeders ( $>1$ foot), whereas the converse was true for giant breed dogs. The authors provide no explanation for this finding. They do not appear to have examined this finding further in relation to the other data that they collected. For example, does the height of the feeder relative to the height of the dog affect the speed at which the dog is able to consume its ration (fast eating was also identified as a risk factor)? However, caution should be taken in over-interpreting the data as the length of time between owner completing the questionnaire and the dog potentially developing a GDV could be almost five years. Therefore, additional interactions sought between the potential risk factors are problematic as owner feed management practices (e.g. feeder used) may have altered over the period studied. Furthermore, the small numbers of dogs affected by GDV within each sub-category (e.g. large breed dog fed from a raised feeder) could mean that these findings are simply chance findings.

The findings from the Glickman et al. (2000) provide an additional possible explanation for the lack of significance identified by the Pipan et al. (2012). The Glickman et al. (2000) specifically studied eleven 'at risk' large and giant breed dogs. Both the control dogs and the GDV dogs were therefore drawn from a similar population of dogs. By splitting the data into large and giant breed dogs they further homogenised the dogs in relation to factors such as height of the dog. By contrast, the Pipan et al. (2012) study used an ad hoc convenience sample of dogs of any type/breed/etc. This lack of relative homogeneity in the study population may have reduced the ability of the study to detect raised feeders as a risk factor for GDV, if the risk posed by feeding from a raised feeder interacted with morphometric measurements such as height of the dog. However, by restricting the population studied to eleven breeds, caution should be exercised in extrapolating the Glickman et al. (2000) findings to other breeds of dogs. The authors do not extend their analysis to look at whether the relevant risk factors identified are present across each breed studied, but this may be due to the small sample size within in each breed of dogs affected by a GDV. There is a need for additional investigation in these areas.

The practical implications of the combined findings are that there is limited evidence in the research area of this PICO. The more convincing of the two studies demonstrates a risk associated with using a raised feeder but only for specific height / size of dog (large versus giant breed) combinations. Neither of the studies found an increased risk associated with feeding from floor height. Consequentially, for the client keen to decrease the risk of their dog developing a GDV, the safest option would be to advise that, in the absence of further research, the dog should be fed from a bowl placed on the floor. If comorbidities exist (e.g. reduced mobility, arthritis) that reduce the ability of the dog to feed from the floor such that feeding from a height is considered beneficial, the practitioner should consider the height of the dog relative to the height of the feeder, and advise accordingly.

\section{Methodology Section}

\begin{tabular}{|r|l|}
\hline \multicolumn{2}{|l|}{ Search Strategy } \\
\hline $\begin{array}{r}\text { Databases searched and dates } \\
\text { covered: }\end{array}$ & $\begin{array}{l}\text { Pubmed }(1900-2017) \text {; Science Direct }(1900-2017) ; \text { Web of } \\
\text { Science }(1970-2017) ; \text { CAB Abstracts }(1983-2016)\end{array}$ \\
\hline Search terms: & $\begin{array}{l}\text { (dogs OR dog OR canine) AND ("gastric dilatation" OR "gastric } \\
\text { dilatation volvulus" OR GDV OR "gastric torsion" OR "stomach } \\
\text { volvulus") AND (feed* OR diet OR diets OR dietary) }\end{array}$ \\
\hline Dates searches performed: & $11^{\text {th } \text { January } 2017}$ \\
\hline
\end{tabular}




\begin{tabular}{|c|l|}
\hline Exclusion / Inclusion Criteria \\
\hline Exclusion: & $\begin{array}{l}\text { Pre-defined exclusion criteria: non English language, popular press } \\
\text { articles, any study lacking a comparator/control }\end{array}$ \\
\hline Inclusion: & $\begin{array}{l}\text { Any comparative (control group utilised) study in which the effect } \\
\text { of height of the feeder on development of a gastric dilation (+/- } \\
\text { volvulus) was investigated. }\end{array}$ \\
\hline
\end{tabular}

\begin{tabular}{|l|c|c|c|c|c|c|}
\hline \multicolumn{1}{|c|}{ Search Outcome } & $\begin{array}{c}\text { Number } \\
\text { of results }\end{array}$ & $\begin{array}{c}\text { Excluded - did } \\
\text { not answer } \\
\text { PICO question }\end{array}$ & $\begin{array}{c}\text { Excluded - } \\
\text { not English } \\
\text { language }\end{array}$ & $\begin{array}{c}\text { Excluded - } \\
\text { conference } \\
\text { abstract only }\end{array}$ & $\begin{array}{c}\text { Excluded - } \\
\text { duplicates }\end{array}$ & $\begin{array}{c}\text { Total } \\
\text { relevant } \\
\text { papers }\end{array}$ \\
\hline NCBI PubMed & 25 & 23 & 0 & 0 & 0 & 2 \\
\hline $\begin{array}{l}\text { Thomson } \\
\text { Reuters Web } \\
\text { of Science }\end{array}$ & 25 & 22 & 1 & 0 & 2 & 0 \\
\hline $\begin{array}{l}\text { CAB Direct } \\
\text { Science Direct }\end{array}$ & 251 & 251 & 1 & 2 & 2 & 0 \\
\hline Total relevant papers when duplicates removed & & 0 & 0 & 0 \\
\hline
\end{tabular}

\section{CONFLICT OF INTEREST}

The author declares no conflict of interest.

\section{REFERENCES}

1. Glickman, L. et al. (2000) Non-dietary risk factors for gastric dilation-volvulus in large and giant breed dogs. Journal of the Veterinary Medicine Association, 217 (10), pp. 1492 1499 http://dx.doi.org/10.2460/javma.2000.217.1492

2. Pipan, M. et al. (2012) An internet-based survey of risk factors for surgical gastric dilation-volvulus in dogs. Journal of the American Veterinary Medicine Association, 240 (12), pp. 1456 -

1462 http://dx.doi.org/10.2460/javma.240.12.1456 


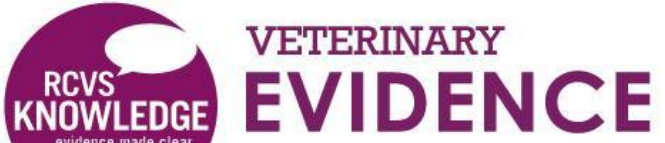 \\ ochese}

\section{Intellectual Property Rights}

Knowledge Summaries are a peer-reviewed article type which aims to answer a clinical question based on the best available current evidence. It does not override the responsibility

of the practitioner. Informed decisions should be made by considering such factors as individual clinical expertise and judgement along with patient's circumstances and owners' values. Knowledge Summaries are a resource to help inform and any opinions expressed within the Knowledge Summaries are the author's own and do not necessarily reflect the view of the RCVS Knowledge.

Authors of Knowledge Summaries submitted to RCVS Knowledge for publication will retain copyright in their work, but will be required to grant to RCVS Knowledge an exclusive license of the rights of copyright in the materials including but not limited to the right to publish, re-

publish, transmit, sell, distribute and otherwise use the materials in all languages and all media throughout the world, and to license or permit others to do so.

Authors will be required to complete a license for publication form, and will in return retain certain rights as detailed on the form.

Veterinary Evidence and EBVM Network are RCVS Knowledge initiatives. For more information please contact us at editor@veterinaryevidence.org

RCVS Knowledge is the independent charity associated with the Royal College of Veterinary Surgeons (RCVS). Our ambition is to become a global intermediary for evidence based veterinary knowledge by providing access to information

that is of immediate value to practicing veterinary professionals and directly contributes to evidence based clinical decision-making.

\section{www.veterinaryevidence.org}

RCVS Knowledge is a registered Charity No. 230886. Registered as a Company limited by guarantee in England and Wales No. 598443.

Registered Office:

Belgravia House

62-64 Horseferry Road

London SW1P 2AF 